\title{
Relationship of Percentage and Oil Yield with the PhysicoChemical Properties of Native Castor Genotypes from Iran
}

\author{
GHANBAR LAEI ${ }^{1}$, MOHAMMAD REZA BIHAMTA ${ }^{* 2}$, \\ REZA AZIZINEZHED' ${ }^{1}$ and FAROKH DARVISHKOJOUR ${ }^{1}$ \\ 'Department of Plant Breeding, Science and Research branch, \\ Islamic Azad University, Tehran, Iran. \\ ${ }^{2}$ Department of Agronomy, Tehran University, Tehran, Iran. \\ ${ }^{*}$ Corresponding author E-mail: pomato1960@yahoo.com \\ http://dx.doi.org/10.13005/ojc/320448
}

(Received: May 22, 2016; Accepted: July 25, 2016)

\begin{abstract}
This study aimed to examine the relationship of percentage and oil yield with the physicochemical properties of native castor genotypes, specifically 28 castor genotypes from 27 native castors and 1 modified castor distributed in Iran. A randomized complete block design with three replications was conducted in 2014 and 2015 at the Research Farm of Islamic Azad University in Damghan, Iran. In the growth period, the following traits were sampled: grain yield, oil percentage, oil yield, weight of 1,000 seeds, length of seeds, width of seeds, grain volume, number of seeds per plant, Relative Water Content (RWC), Seed Color, leaf, vein, stem color, and chlorophyll fluorescence rate. After data were collected, variance analysis was conducted through SAS, and means were compared through Duncan's test at $5 \%$ probability level. Correlation coefficients were calculated, and cluster analysis was performed to group the genotypes. Graphs were drawn with Excel. Results indicated that the studied traits were diverse. The seed oil percentage of the native castor genotypes differed; hence, they were classified into four genotypic groups. At $1 \%$ probability level, seed yield was positively and significantly correlated with oil yield $\left(r=0.85^{\star *}\right)$. This finding indicated that oil yield increased. Thus, oil yield in castor can be decreased. This parameter can also be used as a reference in breeding programs.
\end{abstract}

Keywords: Castor, Genotype, Chlorophyll fluorescence, Oil yield.

\section{INTRODUCTION}

Castor plant (Ricinus communis L.) is a member of Euphorbiaceae ${ }^{1}$. This plant is also called castor oil plant and is sold under the trade name of Neoloid. A hybrid and diploid plant with 20 chromosomes $(2 n=20)$, castor grows in temperate regions, originated from Ethiopia ${ }^{2}$. It is distributed in 
different Iranian regions, including Yazd, Khuzestan, Khorasan, and North. Castor also grows wildly in the central and southern parts of $\operatorname{Iran}^{3}$. More than 700 applications of castor oil, including chemical, sanitary, biodiesel, military, food, and cosmetics industries, have been developed. This plant has also been used to produce herbicides and antiseptics ${ }^{4}$.

\section{The use of castor oil}

Castor oil plant has been used as a pharmaceutical by human since $4000 \mathrm{BC}^{5}$. The presence of many compounds in castor oil is accounted for their pharmacologic properties; for this reason, valuable chemical compounds in castor oil have been utilized in numerous applications. Castor seed contains $40 \%$ to $60 \%$ oil; as such, castor seed is considered a major natural oil source for the production of biofuels used in most developed countries. The diversity of medicinal compounds is also an essential characteristic of castor oil plant ${ }^{6}$. The most popular drugs on the market have been processed with castor oil 7 .8. The Food and Drug Administration of the USA has reported castor oil as safe and effective. According to the Chamber of
Commerce, Industries, Mines, and Agriculture, castor oil imported in Iran in 2015 amounted to 1,118,590 $\mathrm{kg}$ and cost approximately $\$ 1,767,239$ (Table 1).

Chemical properties can be directly influenced by fatty acid composition, triacylglycerol, and oil composition depending on variety and other factors, such as weather conditions and varying soil types ${ }^{8}$. Hydroxyl groups in castor oil can be effective in various applications. Among vegetable oils; castor oil yields the highest oil viscosity and solubility in alcohol (Table 2). Castor oil produces conjugated linoleic acid isomers ${ }^{9}$. Conjugated linoleic acid isomers play an important role in human and animal health.

The first step to identify native genotypes is morphological identification because these traits are easily measurable and are implicated in a wide range of scientific applications ${ }^{3}$. In castor, various growth traits, including leaf diversity, stem color, number and size of leaf lobes, and polished mode of stems, have been described ${ }^{10-11}$. Furthermore, the growth behaviors and plant forms of castor vary

Table 1: Statistics Total" Castor oil and its fractions imports to the country in the year" 2015"

\begin{tabular}{ccccc}
\hline Series & Country & Weight $(\mathbf{k g})$ & Value (Rail) & Value (Dollar) \\
\hline 1 & India & 1056773 & $4.554 \mathrm{E}+10$ & 1553501 \\
2 & Swiss & 350 & $3.067 \mathrm{E}+09$ & 104177 \\
3 & United Arab & 54000 & $2.357 \mathrm{E}+09$ & 78233 \\
& Emirates & & & \\
4 & England & 7300 & $8.461 \mathrm{E}+09$ & 28246 \\
5 & Turkey & 167 & 92502880 & 3081 \\
& & Total & $5.19 \mathrm{E}+10$ & 1767239 \\
\hline
\end{tabular}

Table 2: Properties of castor oil

\begin{tabular}{ll}
\hline Molecular formula & $\mathrm{C}_{3} \mathrm{H}_{5}\left(\mathrm{C}_{18} \mathrm{H}_{33} \mathrm{O}_{3}\right)_{3}$ \\
Molar mass & 932 Daltons \\
Appearance Shape & Colorless or yellowish \\
& liquid \\
Density & $9.61 \times 10-1 \mathrm{~g} / \mathrm{cm} 3$ \\
melting point & $-10^{\circ} \mathrm{C}$ \\
Boiling point & $313^{\circ} \mathrm{C}$ \\
Solubility in water & Very high \\
\hline
\end{tabular}

under different environmental conditions ${ }^{18}$. However, the greatest diversities have been observed in fertility rate, shape, seed color and size, number of flowers in each cluster, pedicle length, and capsule opening $^{10}$.

Foster et al. examined the genotypic diversity of castor in 45 countries and found that the largest diversities are recorded in India with 79 polymorphisms, and in Iran with 25 polymorphisms; by contrast, the smallest diversity is documented in 

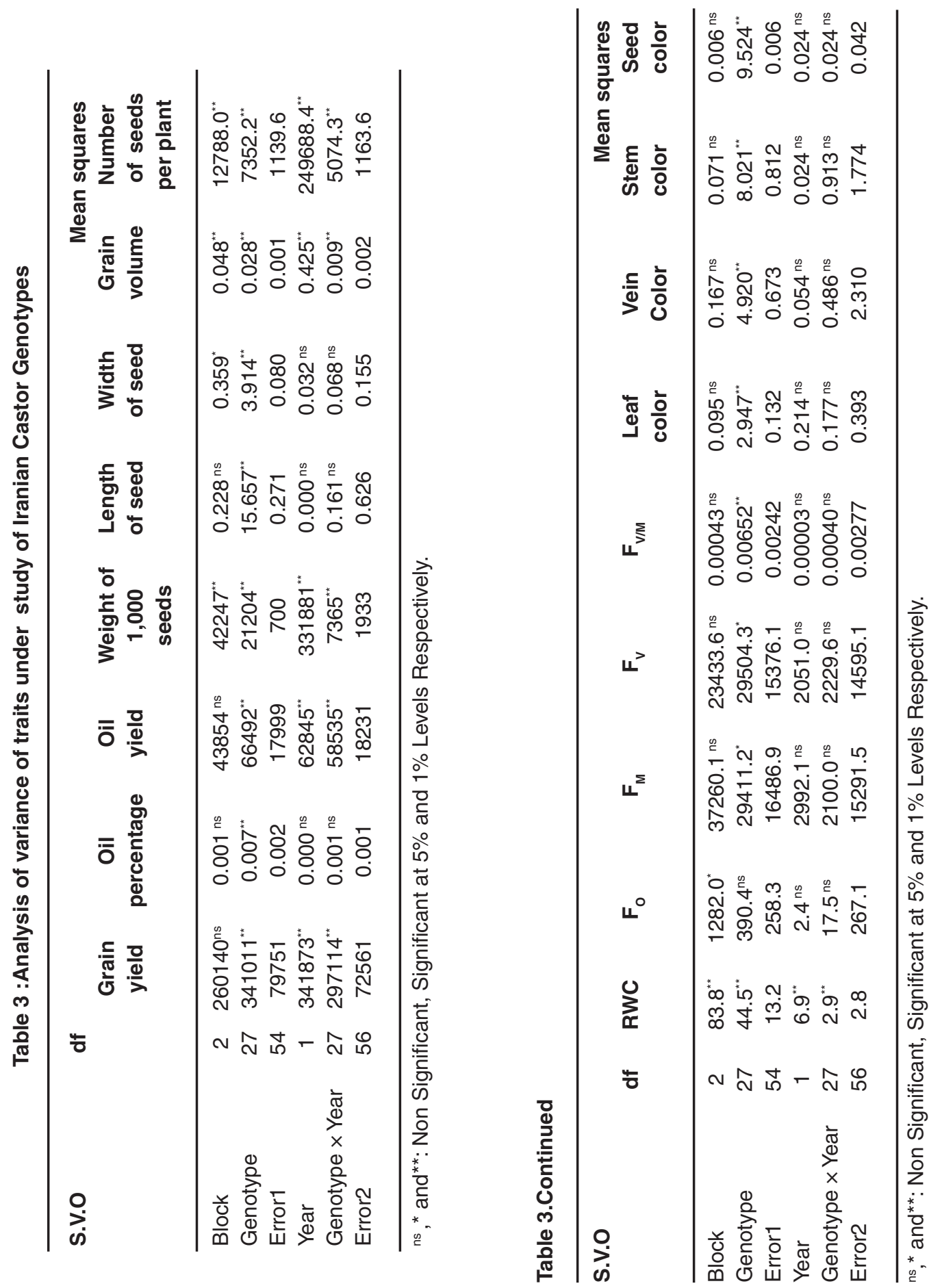
Yugoslavia, with only 1 polymorphism ${ }^{13-25}$. Goodarzi et al. reported a variety in the genetic diversity of 12 native masses of castor exhibiting different traits, such as plant height, number of primary side stems, female flowers, male flowers, fresh weight of the main stem, secondary cluster weight, primary side stem, length of the main stem, secondary side cluster length, dry weight of the main stem, and diameter of the main stem ${ }^{3}$. Anjani investigated two genotypes of the purple morph type of castor and observed that these two genotypes significantly differ from each other; hence, the investigated traits and genotypes should be classified into two separate groups ${ }^{14}$. Shaheen focused on the genetic diversity of castor plants collected from different regions of Egypt, examined 20 morphological traits, and presented two morphological patterns of leaf, pollen, capsule, and seed traits encoded by these native genotypes ${ }^{15}$. Thatikunta et al. genetically investigated 27 castor genotypes and found diversity in 15 traits of roots and stems16. Shidfar et al. explored the agronomic traits of 12 castor genotypes and found that genotype significantly influences the investigated traits ${ }^{17}$. Sayadi Dizaj et al. observed the diversity in the yield and yield components of 12-castor genotypes ${ }^{18}$. The ratio of the number of seeds to the number of capsules in castor is a good criterion to evaluate its seed yield ${ }^{19}$. They further reported that the number of seeds (99\%) and the number of capsules (95\%) in castor are correlated with seed yield.

Castor seed yield per plant, an important trait that is influenced by several factors such as genotype, environment and so is ${ }^{20}$. Therefore, various factors, such as climate conditions, plant population, and growth behavior, influence castor and thus result in yield diversity ${ }^{15}$.

This study aimed to examine the relationship of percentage and oil yield with the physicochemical properties of native castor genotypes, specifically 28 castor genotypes from 27 native castors and 1 modified castor distributed in Iran.

\section{MATERIALS AND METHODS}

To examine the relationship of percentage and oil yield with the physicochemical properties of native castor genotypes from Iran, we investigated 28 castor genotypes (27 native castors and 1 modified castor) by employing a randomized complete block design with three replicates and with a fixed density of five plants in square meters. The study was conducted in 2014 and 2015 at the Research Farm of Islamic Azad University, Damghan (34 $12^{\prime}$ latitude; $53^{\circ}$ and $42^{\prime}$ longitude; $1155.4 \mathrm{~m}$ above sea level). The plants were grown on sandy soil. Crop care, including seedbed preparation and proper use of fertilizer based on soil test, was identical in all of the treatments. In the growth period, the following traits were determined: grain yield, oil percentage, oil yield, weight of 1,000 seeds, length of seed, width of seed, grain volume, number of seeds per plant, RWC, color of seed coat, leaf, vein, stem color, and chlorophyll fluorescence rate on the leaf surface. The chlorophyll fluorescence rate was measured by using a chlorophyll fluorescence set (Opti-Sciences Inc.). Thus, the plant leaves were protected from light with special clips; as a result, they could acclimate in the darkness. Fluorescence parameters, such as fluorescence rate, min (FO) fluorescence, maximum fluorescence $(F M)$, variable fluorescence $(F V)$, and FV-to FM ratio (FV/FM), were measured. After data were collected, variance analysis was conducted with SAS, and means were compared via Duncan's test at $5 \%$ probability level. Correlation coefficients were calculated, and cluster analysis was conducted to group the genotypes. Graphs were drawn with Excel.

\section{RESULTS}

\section{Effects of genotypes on the physicochemical properties of castor}

ANOVA revealed that the corresponding genotypes of the studied traits significantly differed at $1 \%$ probability level in terms of grain yield, oil percentage, oil yield, and weight of 1,000 seeds, length of seed, width of seed, grain volume, and number of seeds per plant, RWC, FV/FM, leaf color, vein color, stem color, and seed color. Moreover, a significant difference was observed at $5 \%$ probability level. By contrast, significant differences were not observed in FO and FV. However, between years for traits, including grain yield, oil yield, weight of 1,000 seeds, grain volume, number of seeds per plant, and RWC, at $1 \%$ difference is significant. The interaction effects of genotype $\times$ year was significant on grain 


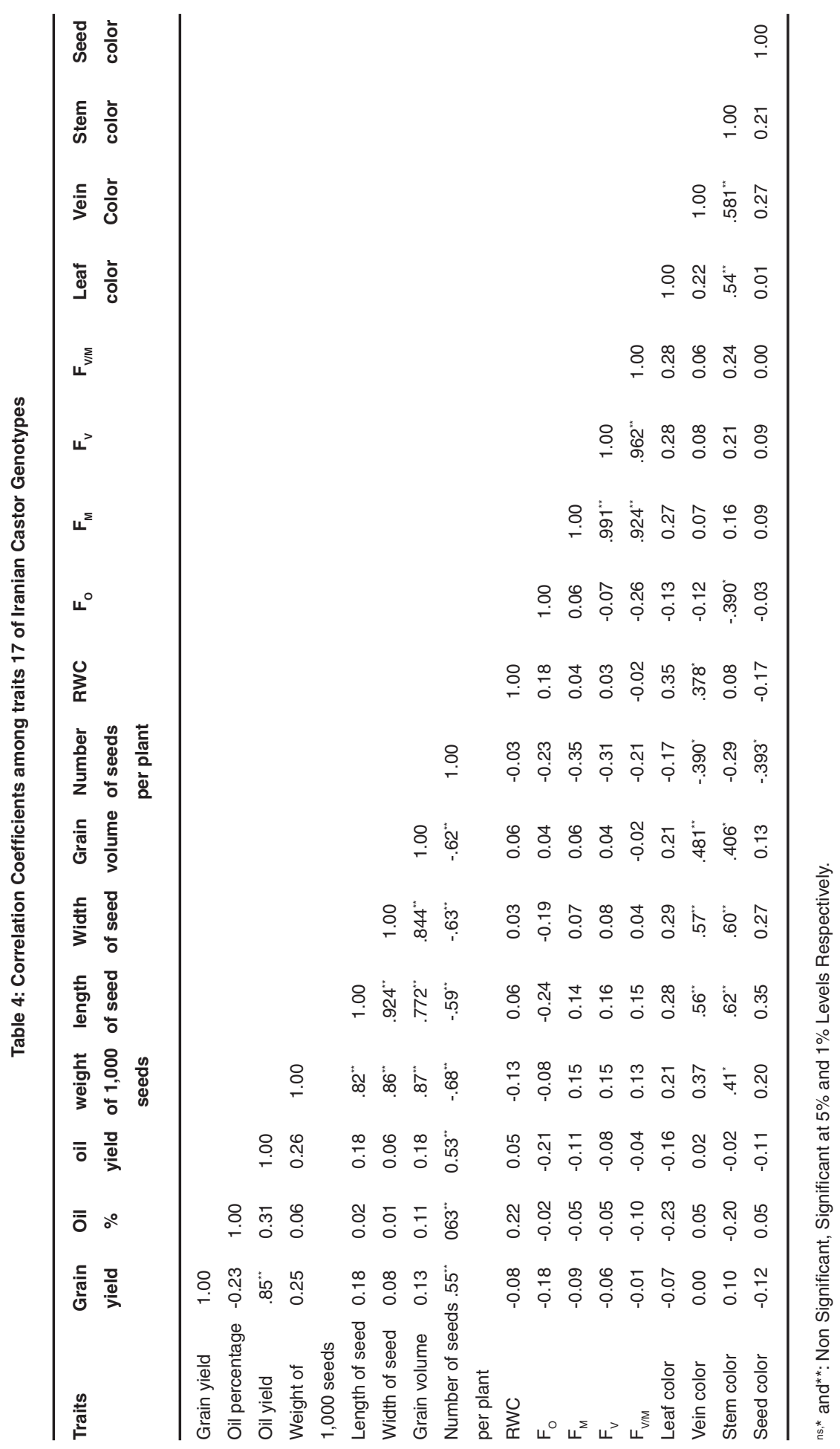


yield, oil yield, weight of 1,000 seeds, grain volume, number of seeds per plant, and RWC at the $1 \%$ level (Table 3).

\section{Leaf color}

The native castor genotypes exhibited four different leaf colors. As such, they were classified into four genotypic groups. The first group with dark green leaves included eight genotypes, namely, Ricindozho, Kashan, Shahrood, Darab, Damghan, Ardebil, 14283, and Tabriz. The second group with green leaves comprised 14 genotypes, namely, Mobarakht, Arak, Semnan, Birjand, Zabol, Urmia, Karaj, 1574, 1083, 1084, Mashhad, Fasa, Yazd, and Ahwaz. The third group with pink leaves consisted three genotypes, namely, Dezful, Maragheh, and 1573. The fourth group with red leaves contained three genotypes, namely, Gachsaran, Jiroft, and Sirjan (Figure 1). Castor plant is characterized by various growth traits, such as leaf, size and number of leaf lobes, and polished mode of stems ${ }^{10-11}$. However, the most evident variety was observed in the shape,

Table 5: Means of traits of Iranian Castor genotypes

(Duncan Multiple Range Test at The Level of 5\%)

\begin{tabular}{|c|c|c|c|c|c|c|}
\hline Genotype & $\begin{array}{l}\text { Grain yield } \\
(\mathrm{kg} / \mathrm{ha})\end{array}$ & $\begin{array}{l}\text { Oil } \\
(\%)\end{array}$ & $\begin{array}{l}\text { Oil yield } \\
\text { (kg/ha) }\end{array}$ & $\begin{array}{l}\text { Weight of } \\
1,000 \\
\text { seeds(gr) }\end{array}$ & $\begin{array}{l}\text { Length of } \\
\text { seed }(\mathrm{mm})\end{array}$ & $\begin{array}{l}\text { Width of } \\
\text { seed }(\mathrm{mm})\end{array}$ \\
\hline Mobarakeh & $1183.02 \mathrm{~g}$ & $0.45 \mathrm{fb}-\mathrm{e}$ & $528.86 f$ & $225.25 i$ & $11.25 \mathrm{gf}$ & $7.95 \mathrm{fg}$ \\
\hline Arak & $1768.96 a-d$ & $0.47 a-d$ & $836.05 a b$ & $265.18 \mathrm{~h}$ & $11.55 \mathrm{ef}$ & $8.16 f$ \\
\hline $\begin{array}{l}\text { Kashan } \\
\text { Semnan }\end{array}$ & $1711.71 \mathrm{~b}-\mathrm{e}$ & $0.46 a-e$ & 795.73a-d & $264.88 \mathrm{~h}$ & $11.92 \mathrm{ed}$ & $7.98 \mathrm{fg}$ \\
\hline $1898.81 \mathrm{ab}$ & $0.41 \mathrm{fde}$ & 787.98a-d & $225.48 \mathrm{i}$ & $10.31 \mathrm{~h}$ & $7.28 \mathrm{~h}$ & \\
\hline Birjand & $1202.15 \mathrm{gf}$ & $0.44 \mathrm{fb}-\mathrm{e}$ & $522.67 f$ & $146.44 \mathrm{k}$ & $8.71 \mathrm{j}$ & $6.55 i$ \\
\hline Zabol & $1413.62 \mathrm{~d}-\mathrm{g}$ & $0.42 \mathrm{fc}-\mathrm{e}$ & $599.69 f e$ & $330.39 \mathrm{~b}-\mathrm{d}$ & 14.03ab & $9.13 b c$ \\
\hline Tabriz & $1569.14 \mathrm{eb}-\mathrm{f}$ & $0.41 \mathrm{fde}$ & $626.49 d-e$ & $330.92 b-d$ & $12.06 \mathrm{ed}$ & $8.86 c-e$ \\
\hline Ardebil & $1437.85 \mathrm{ec}-\mathrm{g}$ & $0.39 f$ & $547.71 \mathrm{ef}$ & $306.66 c-g$ & $12.26 \mathrm{~cd}$ & $8.72 \mathrm{~d}-\mathrm{e}$ \\
\hline Urmia & $1319.97 \mathrm{e}-\mathrm{g}$ & $0.48 a-d$ & $626.79 d-f$ & $209.22 \mathrm{ij}$ & 11.1gf & $7.95 f g$ \\
\hline Karaj & $1427.57 \mathrm{c}-\mathrm{g}$ & $0.43 b-f$ & $622.33 d-f$ & $411.48 \mathrm{a}$ & $14.15 a b$ & $9.52 \mathrm{a}$ \\
\hline 1574 & 1953.92ab & $0.43 b-f$ & 833.53ab & $299.59 d-h$ & $12.87 \mathrm{c}$ & $9.02 \mathrm{~cd}$ \\
\hline Gachsaran & $1604.34 b-e$ & $0.45 b-f$ & 722.03a-e & $288.95 f-h$ & $12.56 \mathrm{~cd}$ & $8.74 d-e$ \\
\hline 1573 & $1820.23 a-c$ & $0.43 \mathrm{~b}-\mathrm{f}$ & $786.39 a-d$ & $228.32 \mathrm{i}$ & $11.19 \mathrm{gf}$ & $8.01 \mathrm{fg}$ \\
\hline 1083 & 1898.38ab & $0.42 d-f$ & $792.96 a-d$ & $227.43 i$ & $11.47 \mathrm{ef}$ & $7.29 \mathrm{~h}$ \\
\hline 1084 & $1585.44 b-e$ & $0.41 \mathrm{fde}$ & $642.21 \mathrm{c}-\mathrm{f}$ & $188.55 \mathrm{j}$ & $10.42 \mathrm{~h}$ & $7.36 \mathrm{~h}$ \\
\hline 14283 & $2134.59 a$ & $0.38 f$ & $806.24 a-d$ & $341.16 \mathrm{bc}$ & 14.17ab & $9.13 b c$ \\
\hline Mashhad & 1936.69ab & $0.41 \mathrm{~d}-\mathrm{f}$ & 791.14a-d & $325.37 \mathrm{~b}-\mathrm{e}$ & $14.11 a b$ & $8.83 c-e$ \\
\hline Fasa & 1934.98ab & $0.42 d-f$ & 806.29a-d & $285.61 f-h$ & $11.13 \mathrm{gf}$ & $8.05 \mathrm{fg}$ \\
\hline Yazd & $1619.01 \mathrm{~b}-\mathrm{e}$ & $0.49 a b$ & 803.83a-d & $302.24 \mathrm{~d}-\mathrm{g}$ & $14.52 \mathrm{a}$ & $8.76 c-e$ \\
\hline Darab & $1601.44 b-e$ & $0.52 a$ & $830.59 a-c$ & $306.71 \mathrm{c}-\mathrm{g}$ & $11.13 \mathrm{gf}$ & $8.05 \mathrm{fg}$ \\
\hline Damghan & $1595.93 b-e$ & $0.4 \mathrm{fe}$ & $650.86 b-f$ & 197.59ij & $9.47 i$ & $6.72 \mathrm{i}$ \\
\hline Ricin donzho & $1602.17 \mathrm{~b}-\mathrm{e}$ & $0.41 \mathrm{~d}-\mathrm{f}$ & $656.77 b-f$ & $214.54 i j$ & $10.56 \mathrm{gh}$ & $7.75 \mathrm{~g}$ \\
\hline Shahrood & 1869.04ab & $0.49 a-c$ & $906.22 a$ & $283 g h$ & $10.56 \mathrm{gh}$ & $7.39 \mathrm{~h}$ \\
\hline Jiroft & $1419.02 d-g$ & $0.47 a-e$ & $667.06 \mathrm{~b}-\mathrm{f}$ & $319.26 b-f$ & $14.42 \mathrm{a}$ & $9.46 a b$ \\
\hline Dezful & $1706.63 b-e$ & $0.43 c-f$ & 727.76a-e & $293.52 \mathrm{e}-\mathrm{h}$ & 13.89ab & $8.8 c-e$ \\
\hline Sirjan & $1676.43 \mathrm{~b}-\mathrm{e}$ & $0.41 d-f$ & $688.05 f b-e$ & $222.85 i$ & $10.65 \mathrm{gh}$ & $7.32 \mathrm{~h}$ \\
\hline Ahwaz & 1901.37ab & $0.43 b-f$ & $825.41 a-c$ & $350.37 b$ & $13.72 b$ & $8.89 c-e$ \\
\hline Maragheh & $1568.26 b-f$ & $0.42 d-f$ & $669.15 b-f$ & $231.05 i$ & $12.25 \mathrm{~cd}$ & $8.58 \mathrm{e}$ \\
\hline
\end{tabular}

Mean Followed By Similar Letters In Each Column are not Significantly Different 
color, and size of seeds, number of flowers in each cluster, pedicle length, and capsule opening. Leaf color was positively and significantly correlated with stem color $\left(r=0.54^{\star *}\right)$ at $1 \%$ probability level (Table 4).

\section{Vein Color}

The native castor genotypes manifested different vein colors. As such, they were classified into four genotypic groups. The first group with white vein included four genotypes, namely, Sirjan, Ahwaz, Dezful, and Kashan. The second group with green vein comprised eleven genotypes, namely, Arak,
1048, Mobarakeh, Maragheh, Zabol, Urmia, Tabriz, Jiroft, Yazd, Mashahd, and 14283). The third group with pink vein consisted of seven genotypes, namely, Karaj, 1274, Fasa, Damghan, Semnan, Birjand, and 1083). The fourth group with red vein contained six genotypes, namely, Ardebil, Gachsaran, 1573, RicinDonzho, Shahrood, and Darab (Figure 2). Leaf color positively and significantly correlated with grain length $\left(r=0.56^{* *}\right)$ and grain width $\left(r=0.57^{* *}\right)$. Therefore, grain length and width increase as veins change their color from white to dark red. As a result, grain weight, yield, and oil yield increase (Table 4).

Table 5. Continued

\begin{tabular}{|c|c|c|c|c|c|c|}
\hline Genotype & RWC (\%) & FM & FV & FV/M & $\begin{array}{c}\text { Grain } \\
\text { volume(cc) }\end{array}$ & $\begin{array}{c}\text { Number of } \\
\text { seeds } \\
\text { per plant }\end{array}$ \\
\hline Mobarakeh & 40.61b-i & 645.33a-d & 421.33a-c & $0.65 c d$ & $0.29 f g$ & $118.75 f-j$ \\
\hline Arak & $44.06 \mathrm{a}-\mathrm{c}$ & 681.67a-d & 474a-c & $0.69 a-d$ & $0.32 d-f$ & 173.01b-e \\
\hline Kashan & 43a-e & 666.33a-d & 454.67a-c & $0.68 a-d$ & $0.26 \mathrm{~g}-\mathrm{i}$ & $162.54 b-f$ \\
\hline Semnan & 42.08a-f & $664 a-d$ & 454a-c & $0.68 a-d$ & $0.25 \mathrm{~h}-\mathrm{j}$ & $180.45 a-d$ \\
\hline Birjand & $38.05 e-i$ & 662.67a-d & 455.67a-c & $0.69 a-d$ & $0.18 \mathrm{k}$ & $176.87 b-d$ \\
\hline Zabol & 40.22b-i & 709.67a-c & $514 a b$ & $0.72 a-c$ & $0.39 a b$ & 108.5h-j \\
\hline Tabriz & $41.46 \mathrm{a}-\mathrm{g}$ & 754.67a-c & $535.67 a b$ & $0.71 a-c$ & $0.34 \mathrm{~cd}$ & $101.02 i j$ \\
\hline Ardebil & 41.33a-h & $809.83 a$ & $595.83 a$ & $0.73 a$ & $0.37 \mathrm{bc}$ & $117.25 f-j$ \\
\hline Urmia & 42.92a-e & 582cd & $371.33 b c$ & $0.63 d$ & $0.23 i j$ & $138.26 \mathrm{~d}-\mathrm{i}$ \\
\hline Karaj & $38.09 e-i$ & $658 a-d$ & $450 a b c$ & $0.68 a-d$ & $0.42 a$ & 79.53j \\
\hline 1574 & 36.27hi & $516.67 d$ & $329 c$ & $0.63 d$ & $0.34 c-e$ & $186.63 a-c$ \\
\hline Gachsaran & 40.62b-i & $626 \mathrm{bcd}$ & $420.67 a-c$ & $0.66 b-d$ & $0.34 c-e$ & $174.8 b-d$ \\
\hline 1573 & $44.59 a-c$ & $608.67 b-d$ & $389.33 b c$ & $0.63 d$ & $0.32 e-f$ & 196.36ab \\
\hline 1083 & 42.63a-e & 695.33a-c & 514.67ab & $0.73 a$ & $0.2 \mathrm{k}$ & $192.66 a b$ \\
\hline 1084 & 42.61a-e & 684.67a-d & $485 a-c$ & $0.7 a-c$ & $0.19 \mathrm{k}$ & $185.91 \mathrm{a}-\mathrm{c}$ \\
\hline 14283 & $39.54 c-i$ & 697.33a-c & 491a-c & $0.69 a-d$ & $0.35 b-d$ & 152.77b-h \\
\hline Mashhad & $37.36 f-i$ & 735a-c & 519ab & $0.71 a-c$ & $0.35 c d$ & $127.83 e-i$ \\
\hline Fasa & $39.69 c-i$ & $730 a-c$ & $521.67 a b$ & $0.71 a-c$ & $0.36 b-d$ & $172.18 \mathrm{~b}-\mathrm{e}$ \\
\hline Yazd & $43.55 a-d$ & 769ab & $565.67 a$ & $0.73 a b$ & $0.39 a b$ & $124.76 f-i$ \\
\hline Darab & $38.79 \mathrm{~d}-\mathrm{i}$ & $790.33 a b$ & $585.67 a$ & $0.73 a$ & $0.28 \mathrm{gh}$ & $113.74 \mathrm{~g}-\mathrm{j}$ \\
\hline Damghan & $41.66 a-g$ & 711.33a-c & 496.67a-c & $0.69 a-d$ & $0.2 \mathrm{k}$ & $198.97 a b$ \\
\hline Ricin donzho & $36.01 i$ & 717a-c & $521.67 a b$ & $0.73 a b$ & $0.21 \mathrm{jk}$ & $222.56 a$ \\
\hline Shahrood & $39.65 c-i$ & $712.5 a-c$ & $504.67 a b$ & $0.7 a-c$ & $0.32 d-f$ & $162.91 b-f$ \\
\hline Jiroft & 44.82ab & 778.33ab & $579 a$ & $0.74 a$ & $0.35 b-d$ & $110.46 \mathrm{~g}-\mathrm{j}$ \\
\hline Dezful & $38.3 e-i$ & 783.5ab & $582 a$ & $0.73 a$ & $0.27 \mathrm{~g}-\mathrm{i}$ & $143.04 c-i$ \\
\hline Sirjan & $36.97 g-i$ & 786ab & $578.67 a$ & $0.73 a$ & $0.22 \mathrm{kj}$ & $155.61 \mathrm{~b}-\mathrm{g}$ \\
\hline Ahwaz & 42.94a-e & $640.17 a-d$ & 437.33a-c & $0.68 a-d$ & $0.36 \mathrm{bc}$ & $144.25 c-i$ \\
\hline Maragheh & $46.13 a$ & $783.5 a b$ & $582 a$ & $0.73 a$ & $0.3 f e g$ & 153.18b-h \\
\hline
\end{tabular}

Mean Followed By Similar Letters In Each Column are not Significantly Different. 


\section{Stem Color}

The native castor genotypes display different stem colors (Table 3). As such, they were classified into five genotypic groups. The first group with dark green stem included three genotypes,

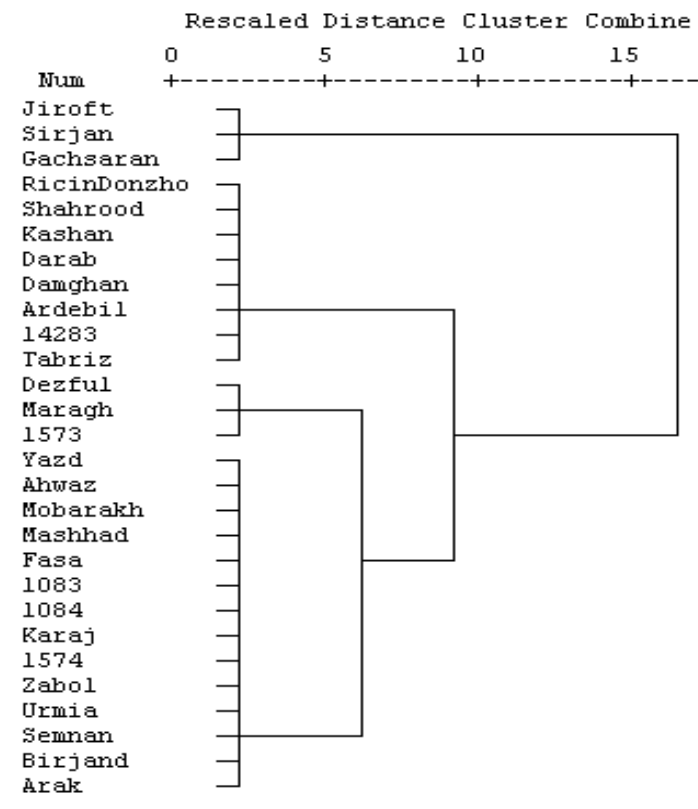

Fig. 1: Result leaf color from cluster analysis of Iranian castor genotypes

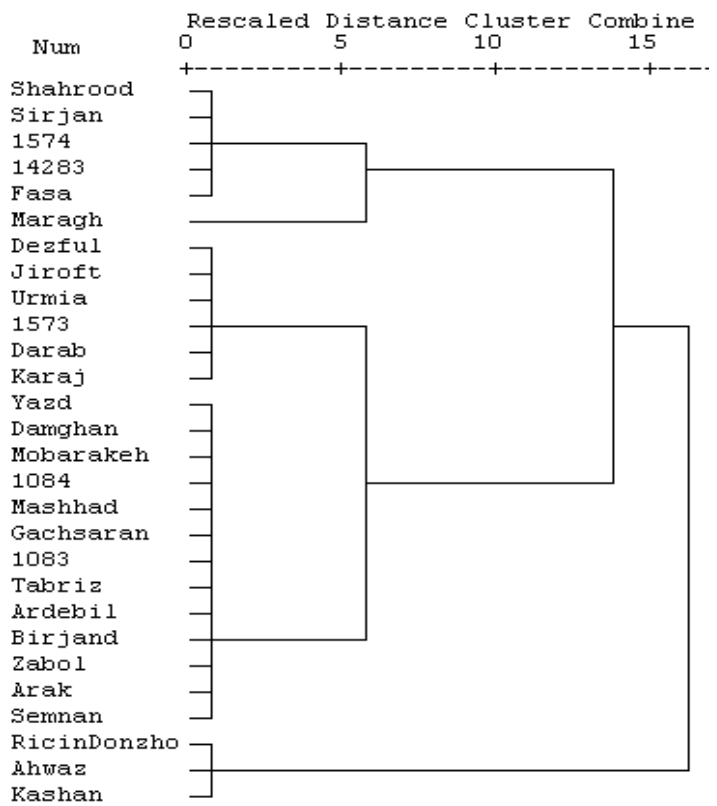

Fig. 3: Result Stem Color from cluster analysis of Iranian castor genotypes namely, Kashan, RicinDonzho, and Ahwaz. The second group with green stem comprised six genotypes, namely, Urmia, Karaj, 1573, Jiroft, Farab, and Dezful. The third group with pink stem consisted of thirteen genotypes, namely, Gachsaran, Mashahd,

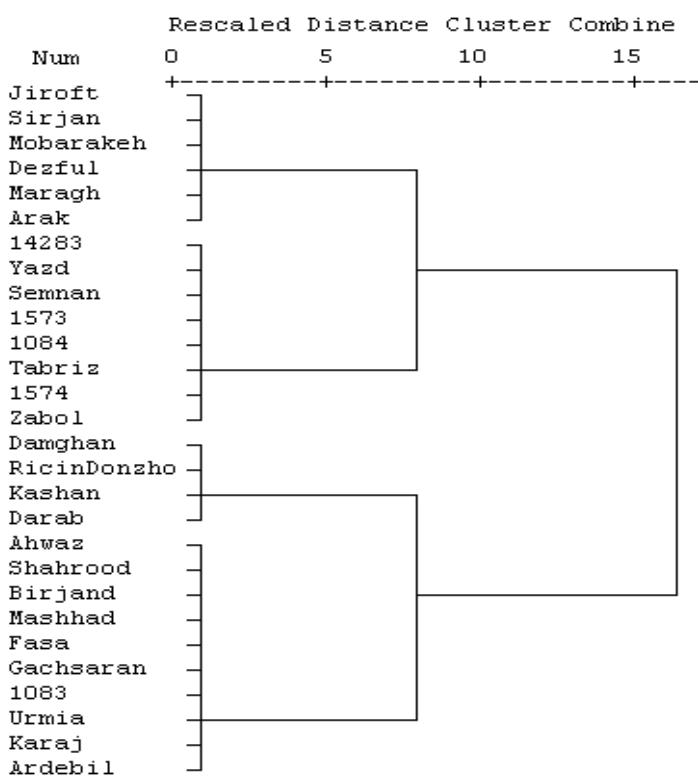

Fig. 2: Result Vein color from cluster analysis of Iranian castor genotypes

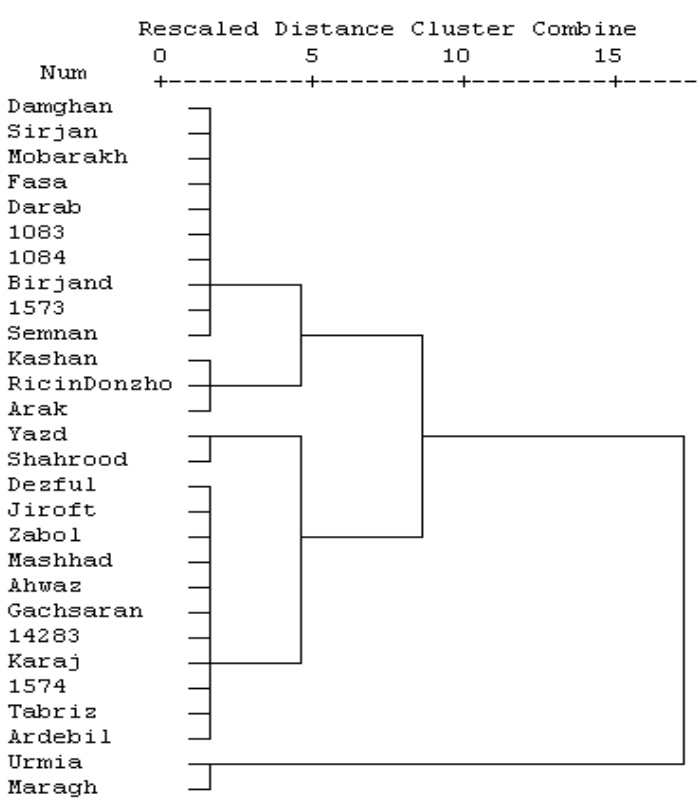

Fig. 4: Result Seed Color from cluster analysis of Iranian castor genotypes 


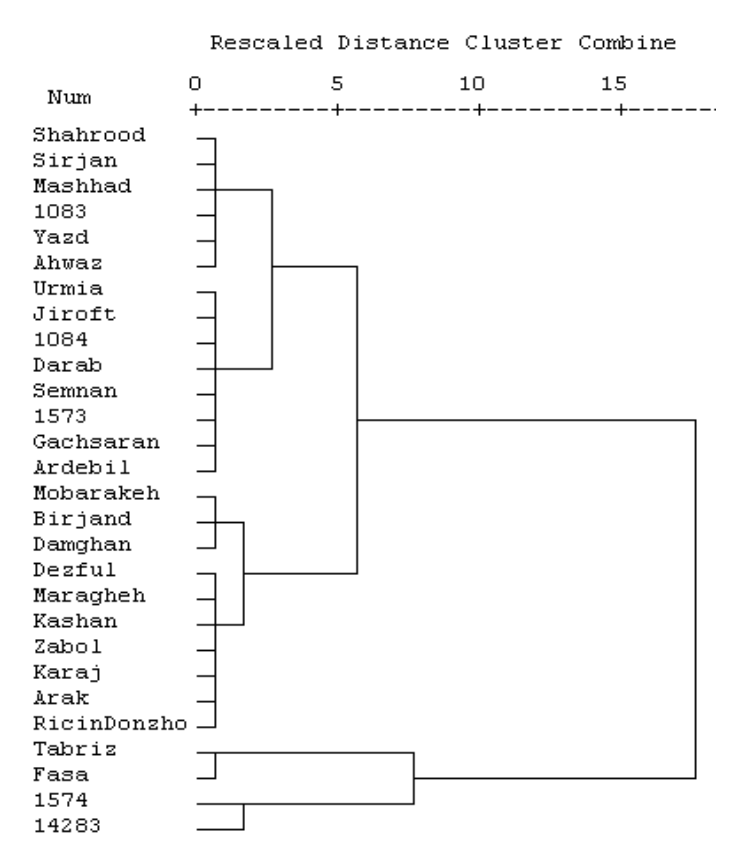

Fig. 5: Result grain yield from cluster analysis of Iranian castor genotypes

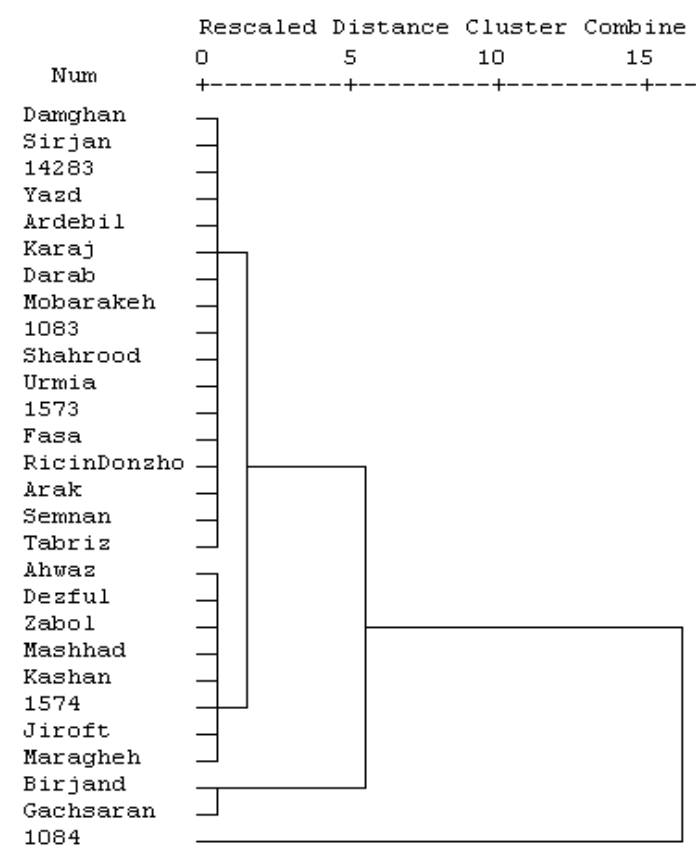

Fig. 6: Result oil percentage from cluster analysis of Iranian castor genotypes

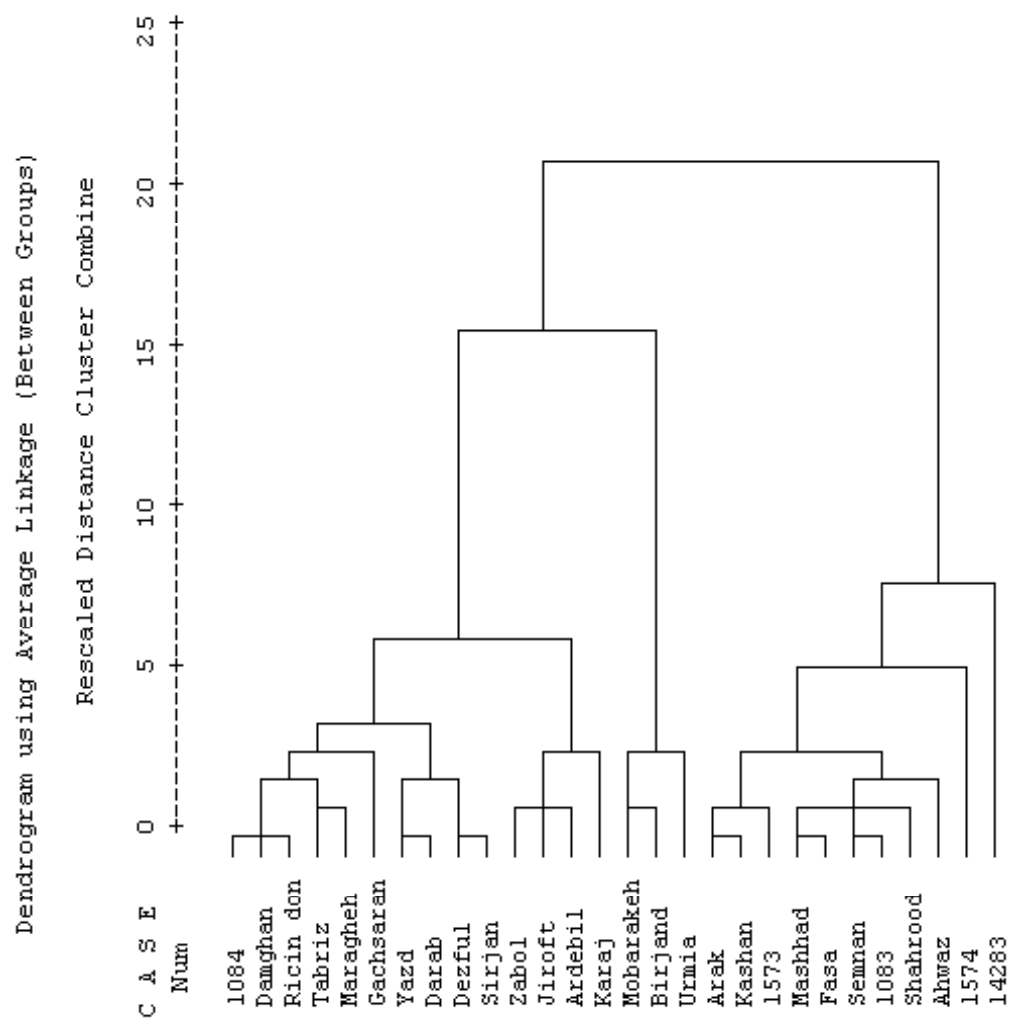

Fig. 7: Result Studied Characters of Iranian Castor Genotypes from cluster analysis 
1083, Ardebil, Damghan, Tabriz, Zabol, Semnan, Yazd, Birjan, 1048, Arak, and Mobarakeh. The fourth group with red stem contained five genotypes, namely, Fasa, 14283, 1574, Shahrood, and Sirjan. The fifth group with dark red stem included one genotype, namely, Maragheh (Figure 3). A wide diversity was observed in growth traits, such as stem color of castor plant ${ }^{10,11-27}$. Stem color was positively and significantly correlated with grain length $\left(r=0.62^{* *}\right)$ and grain width $\left(r=0.60^{* *}\right)$ at the $1 \%$ level. This finding indicated that grain length and width increase as stem color changes from white to dark red. At high latitudes, seed weight, yield, and oil yield increase (Table 4).

\section{Seed Color}

The native castor genotypes showed different Seed Colors (Table 3). As such, they were classified into five genotypic groups. The first group with white seed coat included three genotypes, namely, Kashan, Arak, and RicinDonzho. The second group with black seed coat included ten genotypes, namely, Mobarakeh, Semnan, Birjand, 1573, 1083, 1084, Fasa, Darab, Damghan, and Sirjan. The third group with pink seed coat consisted of 11 genotypes, namely, Ahwaz, Mashhad, 14283, Gachsaran, 1574, Karaj, Ardebil, Tabriz, Zabol, Jiroft, and Dezful. The fourth group with dark red seed coat comprised two genotypes, namely, Yazd and Shahrood. The fifth group with black seed coat included two genotypes, namely, Urmia and Maragheh (Figure 4). Differences in fertility rate, shape, color and seed size, number of flowers in a cluster, pedicle length, and capsule opening ${ }^{11}$.

\section{Grain yield}

The native castor genotypes resulted in different grain yields (Table 3). Therefore, they were classified into six genotypic groups. The first group with very low yield included three genotypes, namely, Damghan, Birjand, and Mobarakeh. The second group with low yield comprised seven genotypes, namely, Karaj, Kashan, Arak, Zabol, RicinDonzho, Maragheh, and Dezful. The third group with moderate yield consisted of eight genotypes, namely, Gachsaran, Darab, Jiroft, 1084, Urmia, Semnan, Ardebil, and 1573. The fourth group with high yield contained six genotypes, namely, Shahrood, 1083, Ahwaz, Mashahd, Yazd, and Sirjan. The fifth group with very high yield included two genotypes, namely, 14283 and 1754 (Figure 5).

The highest seed yield was observed in the native genotype of 14283 with $2134.6 \mathrm{~kg}$ per hectare, and the lowest seed yield was detected in the native genotype of Mobarakeh with 1183.02 $\mathrm{kg}$ per hectare. Although other genotypes were classified among the highest or lowest grain yield groups, the lowest and highest yields were recorded in the two aforementioned genotypes (Table 5). The least and most productive native genotypes were compared by considering various traits, such as weight of 1,000 seeds, seed length, and seed width. Thus, differences were observed in the seed yield of the genotypes investigated in this experiment. These results were consistent with the findings of ${ }^{11,19-21}$. Genotype 14283 exhibited a higher seed yield and weight of 1,000 seeds8. The seed yield of the castor plant depended on environmental conditions. Seed yield was positively and significantly correlated with oil yield $\left(r=0.85^{\star \star}\right)$ at $1 \%$ probability level. This result indicated that oil yield increased as the seed yield increased (Table 4). Nevertheless, the weight of 1,000 seeds was not significantly related to seed yield, consistent with another study ${ }^{18}$. Sarwar and Chaudhry investigated the effects of various traits, such as ripping time, plant height, number of clusters, length of main cluster, number of capsules in the main cluster, capsule weight, and weight of 100 seeds, on the yield of 16 castor genotype mutants with gamma radiation to determine the proper criterion for ideal types with high yield ${ }^{21}$. A significant, positive correlation was seen between number of clusters, capsule weight, weight of 100 seeds and grain yield.

\section{Weight of 1,000 seeds}

The native castor genotypes yielded different weights of 1,000 seeds (Table 3 ). The highest and lowest weights of 1,000 seeds were 411.48 and $146.44 \mathrm{~g}$ for Karaj and Birjand genotypes, respectively. Therefore, the weight of 1,000 seeds differed. Karaj exhibited a higher weight of 1,000 seeds than the other genotypes in the same group. This finding can be a useful reference to achieve future breeding objectives (Table 5). Several researchers have related the differences in the weight of 1,000 seeds to genotype and environmental 
conditions $^{22-24}$. Other researchers related this difference only to genotype ${ }^{18-19}$.

\section{Width and length of seeds}

The native castor genotypes manifested different widths and lengths of seeds (Table 3). The maximum seed length was $14.52 \mathrm{~mm}$ recorded in Yazd, and the maximum width was $9.52 \mathrm{~mm}$ documented in Karaj. The minimum seed length was $8.71 \mathrm{~mm}$ and the minimum width was $6.55 \mathrm{~mm}$ observed in Birjand (Table 5). The weight of 1,000 seeds was positively and significantly correlated with the seed length $\left(r=0.83^{* *}\right)$ and seed width $\left(r=0.86^{\star *}\right)$ at $1 \%$ probability level. This finding revealed that the weight of 1,000 seeds increased as these two traits increased. As a result, seed yield improved (Table 4).

\section{Oil percentage}

The native castor genotypes exhibited different seed oil percentages (Table 3). Thus, they were classified into four genotypic groups. The first group with low seed percentage included 17 genotypes, namely, Ardebil, Mobarakeh, Urmia, Tabriz, Yazd, 14283, 1084, Arak, Sirjan, Darab, Shahrood, RicinDonzho, 1573, 1083, Semnan, Damghan, Fasa, and Karaj. The second group with medium percentage consisted of eight genotypes, namely, Dezful, Ahwaz, Mashhad, Zabol, Kashan, 1574, Jiroft, and Maragheh. The third group with high percentage comprised two genotypes, namely, Gachsaran and Birjand. The fourth group with very high percentage included one genotype, namely, 1084 (Figure 6).

\section{Fluorescence parameters}

The native castor genotypes exhibited different maximum fluorescence rates and FV/FM. By contrast, FV and FO did not differ (Table 3). The following parameters were positively and significantly correlated at $1 \%$ probability level: $\mathrm{FM}$ and $\mathrm{FV}$ $\left(r=0.92^{* *}\right) ; \mathrm{FV} / \mathrm{FM}\left(r=0.99^{* *}\right)$; and $\mathrm{FM}$ and FV/FM $\left(r=0.96^{\star \star}\right)$. This finding indicated that other fluorescence variables (FO, FV, FM, and FV/FM) are altered as each of the fluorescence variables changes. The following parameters also exhibited a positive and significant correlation: leaf color and FV $\left(r=0.56^{\star \star}\right)$; leaf color and FM $\left(r=0.48^{\star \star}\right)$; stem color and FV $\left(r=0.63^{\star \star}\right)$; and stem color and FM/FV $\left(r=0.54^{\star *}\right)$. This finding revealed that the fluorescence rate increased as leaf and stem colors changed (Table 4).

\section{Oil yield}

The results of analysis of variance showed that oil yield had significant difference among castor Genotype at $1 \%$ probability level. Table comparing means showed that the maximum oil yield were obtained by the Ahwaz Genotype with 906.22 $\mathrm{kg}$ per hectare and lowest oil yield achieved by Mobarakeh Genotype with 528.86 kg per hectare (Table 5). Ahwaz genotype by maximum seed yield and oil content were; therefor, these traits can significantly effect on oil yield. Although Ahwaz genotype had characterized by lowest levels for the traits, such as grain weight, grain length and width but shall proposed Ahwaz genotype as a superior genotype in breeding programs because of its high oil percentage.

This study was conducted to identify genotypes with high oil yield. The results showed that genotype Ahvaz has high oil content than other genotypes. Castor oil a genetic trait that is depends has to genotype, environmental conditions and cultivation practices and harvesting time. In this study, seed yield was positively correlated with oil yield, and a significant risk was observed $\left(r=0.85^{* *}\right.$; Table 4). Cluster analysis revealed that the traits of castor native genotypes could be divided into two main groups. The first group includes 1084, Damghan, Ricindozho, Tabrizu, Mobarakht, Gachsaran, Yazd, Darab, Dezful, Sirjan, Zabol, Jiroft, Ardebil, Karaj, Maraghehe, Birjand, and Urmia. The other group comprises Arak, Kashan, 1573, Mashhad, Fasa, Semnan, 1083, Shahrood, Ahwaz, 1574 , and 14283. The subgroups in each group were treated with the greatest similarity (Figure 7).

\section{CONCLUSION}

Evaluation of plants' genetic diversity is vital for modification and preservation of inheritance reserves. Knowledge of plants' genetic diversity is very important for selection of suitable parents for hybridization and obtaining suitable results. Phenotype evaluation may help collection management, species identity validation, error diagnosis in identification and determination of phenotype relations in hybrid species and their parents, rather than usage for 
plants classification ${ }^{26}$. Diversity of leaf color, vein colors, stem color, and seed color were observed in this research. There were four color types (dark green, red, pink, green) in leaf genotypes; four color types (red, pink, green, white) in vein genotypes; 5 color types (red, pink, green, dark green, dark red) in stem genotypes; and 5 color types (black, white, bright black, pink, hepatic red) in seed genotypes. A wide diversity was observed especially in the growth traits such as stem color of the castor plant ${ }^{10,11-18}$. Popova and Moshkin (1986) reported variety in the fertility rate, shape, color, seed size, number of flowers in a cluster, pedicle length, and capsule opening ${ }^{10}$. Popova and Moshkin (1986) and Savy-Filho (2005) reported varieties in the growth traits of the castor plant, such as leaf, size and number of leaf lobes, and polished mode of the stems ${ }^{10-11}$. However, the most evident variety was observed in the seed shape, color, and size; number of flowers in each cluster; pedicle length; and capsule opening. Since these are genetic changes due to the environmental conditions, it is recommended to do new studies due to the importance of anthocyanin. Other scholars also have reported diversity in leaves, stems, etc ${ }^{14-15}$. Furthermore, the highest and lowest oil percentages were $52 \%$ and $38 \%$ recorded in Darab and 14283, respectively. Seed weight is positively related to oil percentage ${ }^{22-24}$. However, this finding was contrary to our results. Seed weight is negatively related to oil percentage $\left(r=-0.65^{\star \star}\right)$, but this finding was in consistent with our results ${ }^{18}$. The oil percentage in castor seed is a genetic trait influenced by various factors, including genotype, environmental conditions, agricultural operations, and harvest time and so on ${ }^{23}$. The amount and ingredients of castor oil are related to climate, cultivar, and cultivation and processing methods7. The oil percentage in trade varieties normally differs between $40 \%$ and $60 \%$. Oil yield is a combination of seed yield and oil content6. Therefore, a reduction in the seed yield decreases oil yield ${ }^{17}$. In this study, the positive correlation between seed yield and oil yield significant risk was observed $\left(r=0.85^{* *}\right)$. 1000 -seeds weight had a positive and significant relation with seed width, Length seed, Grain volume and stem color $\left(r=0.82^{* *}, 0.86^{\star *}, 0.87^{* *}, 0.41^{\star}\right)$, but it had a negative and significant relation with number of seeds $\left(r=-0.68^{* *}\right)$. Number of seeds per plant had a positive and significant relation with seed yield, oil yield, and Oil percentage $\left(0.55^{\star *}, 0.53^{\star \star}, 0.63^{\star}\right)$. This was due to the positive role of seeds per plant with seed yield, and oil yield, which is compatible with the results of SayadiDizaj et al. (2010), who studied 12 native masses to achieve productive masses ${ }^{18}$. Kittock et al. (1967) and Koutroubas et al. (2000) reported a positive relationship between the seed weight and the oil percentage, which was contrary to the findings in accordance with the findings of the present study22-24. However, SayadiDizaj et al. (2010) reported a negative relationship between the seed weight and the oil percentage $\left(r=-0.65^{\star \star}\right)$ which was contrary to the findings the present study. According to Laureti and Marras (1995), the oil percentage in the castor seed is a genetic trait that is influenced by the genotype, environmental conditions, agricultural operations, harvest time, and so on . Weiss (2000) reported that the amount and ingredients of castor oil are related to the climate, cultivar, and cultivation and processing methods ${ }^{7}$. The oil yield is a combination of seed yield and amount of oil. Therefore, a reduction in the seed yield reduces the oil yield ${ }^{17}$. However, number of seeds per plant had a negative and significant relation with 1000-seeds weight, seed length, seed width, Grain volume and Vein $\left(r=-0.68^{\star *},-0.59^{\star *},-0.63^{\star *},-0.62^{\star},-0.32^{\star}\right)$. This indicates that seeds per plant is decreased by 1000 -seeds weight. Since, number of seeds per plant is more effective on seed and oil yield than 1000-seeds weight, it can be used as an important attribute in this research. The highest seed yield was in the native genotype of 14283 with $2,2134.59 \mathrm{~kg}$ per hectare and the lowest seed yield was in the native genotype of Mobarakeh with $1183.03 \mathrm{~kg}$ per hectare. Although other genotypes were classified among the highest or lowest seed yield groups, the lowest and highest yields were observed in the two aforementioned genotypes These results were in accordance with the findings of Koutroubas et al. (1999) $^{18}$, RezvaniMoghadam et al. (2008)19, and SayadiDiza et al. (2010) 22 .

Sarwar and Chaudhry (2008) investigated traits, such as the ripping time, plant height, number of clusters, length of main cluster, number of capsules in the main cluster, capsule weight, and weight of 100 seeds, in the yield of 16 castor genotype mutants with gamma radiation to find the proper criterion for the ideal types with high yield ${ }^{21}$. 
They found a significant positive relationship between the capsule weight and yield and the number of clusters, capsule weight, and weight of 100 seeds, which has a strong and positive effect on the seed yield. the cluster analysis showed The similar genotypes are placed in one group by categorizing them and valuable attributes of each group were identified for probable hybridization. Also, the genotypes of groups with some attributes with higher than average values can be used for ethnical improvement programs.

\section{ACKNOWLEDGEMENTS}

The authors are grateful to the Science and Research Branch, Islamic Azad University, Tehran for providing facilities to conduct and complete this study. The authors declare that there is no conflict of interest.

\section{REFERENCE}

1. Vivodík; M.; Balazova; Z.; Galova; Z. Int. J. Agricultural. 2014, 8, 648-651.

2. Anastasia; U.; Sortinoa; O.; Cosentinoa; S.L.; Pataneb; C. Int. J. Plant Product. 2015; 9; 1-18.

3. Goodarzi, F.; Hasani, A.; Darvishzadeh, R.; Hassanzadeh, A. j. Genetika, 2015, 47, 265 -274 .

4. Farhadi; N.; Souri; M.; Alirezaloo; A.; Rabi Angoorani; H. J. Crop Product. 2012; 9; 89104.

5. Alirezalu, A.; Alirezalu, K.; Karimzadeh, G.; Omidbaigi, R. J. Medicinal plants. 2011, 4, 97-106.

6. Mohammadi, A. Master thesis. 2012, 160.

7. Weiss, E. A. Blackwell Scientific Ltd., Oxford, England. 2000, 13-52.

8. Ogunniy, D.S. J. Bioresource Technology. 2006, 97, 1086-1091.

9. Villeneuve, P.; Lago, R.; Barouh, N.; Barea, B.; Piombo, G.; Dupre, J.Y.; Guillou, A.L.; Pina, M. J. Amer. Oil Chemists. 2005, 82, 261-269.

10. Popova, M.G.; Moshkin,V.A. Botanical classification.1986, 11-27.

11. Savy Filho, A. Campinas: Emopi. 2005, 125.

12. Webster, G.L. Annals of the Missouri Botanical Garden. 1994, 81, 3-32.

13. Foster, J.T.; Allan, G.J.; Chan, A.P.; Rabinowicz, P.D.; Ravel, J.; Jackson, P.J.; Keim, P. BMC Plant Biology. 2010, 10, 1-11.

14. Anjum, F.; Yaseen, M.; Radula, E.; Wahid, A.; Anjum, S. pakistan j. agricultural sciences. 2003a, 40, 43-44.
15. Shaheen, A. M. Pak istan j. Biological Sciences. 2002, 5, 1202-1206.

16. Thatikunta, R.V.; Prasad, O.; Durga, M.M.K. j. Agricultural Science Digest. 2001, 21, 5960.

17. Sharifinia F.D.; Asadi N. Iranian j. of botany. 2002, 9, 135-139. (In Persian).

18. SayadiDizajYekan, A.; Roshdi; M.; Hosseinzadeh, A.; Khorshidi, M.B. J. Research in Agricultural Sciences. 2010, 2, $1-17$.

19. RezvaniMoghadam, P.; Boroumand, Z.; Mohammadabadi, A. A.; Sharif, A. Journal of Researches agricultural Iran. 2008, 6, 303313.

20. Jannavard, Sh.; Tajbakhsh, M.; Bernosi, A. National Congress of oilseed plants of Isfahan University, Isfahan (In Persian). 2009, 359361.

21. Sarwar, G.; chaudhry, M.B. Spanish J. agricultural Research. 2008, 6, 629-634.

22. Kittock, D.L.; Williams, J.H.; Hanway, D.G. Agronomy Journal. 1967, 59, 463-467.

23. Laureti, D.; Marras, G. European J. of Agronomy. 1995, 4, 229-235.

24. Koutroubas; S.D.; Papakosta; D.K.; Doitsinis; A. European Journal of Agronomy. 1999; 11; 227-237.

25. Allan; G.; Williams A.; Rabinowicz P.D.; Chan A.P.; Ravel J.; Keim P. j. Gen. Resources and Crop Evolution. 2008, 55, 365-378.

26. Mousavi, S.H.; Hassandokht, M. R.; Choukan, R.; Sepahvand, N. A.; Khosrowshahli, M. j. crop breeding. 2013, 3, 103-121 